\title{
Short segment Barrett's oesophagus: prevalence, diagnosis and associations
}

\author{
S Nandurkar, N J Talley, C J Martin, T H K Ng, S Adams
}

\begin{abstract}
Background-Prevalence of short segment Barrett's (SSB) oesophagus, defined as the absence of macroscopic Barrett's but histologically identifiable intestinal metaplasia, has been reported to be $18 \%$ based on haematoxylin and eosin (H\&E) staining.

Aims-To define the prevalence of SSB oesophagus using H\&E and alcian blue staining and to determine whether SSB oesophagus is associated with inflammation at the gastro-oesophageal junction (GOJ).
\end{abstract}

Subjects-Consecutive patients $(n=158)$ presenting for endoscopy completed a structured interview.

Methods-Two biopsy specimens taken from the GOJ were stained with H\&E, alcian blue and Giemsa. A third specimen was obtained from the distal oesophagus. Intestinal metaplasia was diagnosed if goblet cells were definitely identified by two independent observers.

Results-SSB oesophagus was present in 46 (prevalence 36\%, 95\% confidence interval (CI) $28 \cdot 5-43 \cdot 5$ ) using alcian blue staining. If $H \& E$ had been the sole staining method used, $50 \%$ cases of intestinal metaplasia would have been overlooked. There were no cases of intestinal metaplasia identified by $H \& E$ but missed by alcian blue staining. Logistic regression analysis identified age (odds ratio (OR) per decade $1 \cdot 03$, 95\% CI 1.01-1.06), histological oesophagitis (OR 3.2, 95\% CI $1 \cdot 4-7 \cdot 2)$ and inflammation at the gastrooesophageal junction (OR 5.9, 95\% CI $2 \cdot 2-15 \cdot 6$ ) as independent risk factors for SSB oesophagus.

Department of Medicine, University of Sydney, Australia $S$ Nandurkar N J Talley

Department of Surgery, University of Sydney, Australia C J Martin

Department of Pathology, Nepean

Hospital

Tospital

$\mathrm{S}$ Adams

Correspondence to: NJ Talley, Professor of Medicine, Clinical Sciences Building, PO Box 63, Penrith NSW 2751, Australia.

Accepted for publication 23 December 1996
Conclusion-Unrecognised SSB oesophagus is highly prevalent in patients presenting for diagnostic upper endoscopy if alcian blue staining is applied.

(Gut 1997; 40: 710-715)

Keywords: Barrett's oesophagus, gastro-oesophageal reflux, histology, intestinal metaplasia.

Traditionally, Barrett's oesophagus is defined as the replacement of the distal oesophageal lining by three or more centimetres of circumferential columnar epithelium in continuity with the gastric mucosa. ${ }^{1}$ However, the length of three centimetres, as required by the above definition, is purely arbitrary. The standard definition excludes tongues of columnar epithelium that are often seen at the gastrooesophageal junction. ${ }^{1}$ Some investigators have recommended that the definition should be more appropriately based on the histological type rather than length. ${ }^{2}$ Cardia or junctional type epithelium in the distal oesophagus is not diagnostic of Barrett's oesophagus, ${ }^{3}$ but detection of specialised intestinal epithelium (as indicated by the presence of goblet cells) is abnormal. In patients who fail to fulfil the traditional definition, the presence of specialised intestinal epithelium has been referred to as short segment Barrett's oesophagus. ${ }^{2}{ }^{3}$

Barrett's oesophagus is a strong risk factor for adenocarcinoma of the oesophagus. ${ }^{4-9}$ The neoplastic risk seems to be related to the presence of specialised intestinal type epithelium, and not the junctional or cardia types. ${ }^{1011}$ There is increasing evidence that these adenocarcinomas can arise from very short segments of metaplastic epithelium. ${ }^{6}{ }^{12}$ Short segments of Barrett's oesophagus may often be overlooked during routine endoscopy because the gastro-oesophageal junction appears to be normal and biopsy specimens are not obtained. In a recent study, the prevalence of short segment Barrett's oesophagus was reported to be $18 \% .^{13}$ Another preliminary report found a prevalence of $24 \% .{ }^{14}$ However, the true prevalence in the community is still unclear as these studies used haematoxylin and eosin $(\mathrm{H} \& \mathrm{E})$ staining alone to detect the specialised intestinal type epithelium. Alcian blue has been shown to be superior to $H \& E$ in detection of intestinal metaplasia, ${ }^{415}$ but this method of diagnosis has not been evaluated in patients without standard Barrett's oesophagus. We hypothesised that the prevalence of short segment Barrett's oesophagus has been underestimated because of the methods used.

Barrett's oesophagus has been causally linked to chronic gastro-oesophageal reflux disease in humans ${ }^{16-18}$ and in experimental models of Barrett's oesophagus, ${ }^{19-22}$ but in the only published paper on short segment Barrett's oesophagus, symptoms of gastrooesophageal reflux were not associated with the condition. ${ }^{13}$ This study did not evaluate the association of short segment Barrett's oesophagus with inflammation of the gastro-oesophageal junction. We postulated that such a link would be detected. Hence, we aimed to estimate the prevalence, compare different methods of diagnosis and assess for associations of short segment Barrett's oesophagus in consecutive patients presenting for endoscopy. 


\section{Methods}

SUBJECTS

Consecutive outpatients booked for routine gastroscopy at Nepean Hospital (irrespective of their indication) were invited to participate in this study. The study was approved by the Wentworth Area Health Service Research and Ethics Committee. Patients were excluded from the study if they had known Barrett's oesophagus, were unwilling to participate or had conditions that did not permit a safe biopsy (for example, coagulopathy, oesophageal varices).

\section{SYMPTOMS}

All patients completed a structured interview that measured symptoms of gastro-oesophageal reflux disease (that is, heartburn, acid regurgitation and dysphagia). All subjects were interviewed individually by one of us ( $\mathrm{SN}$ ) and all the terms were specified to minimise measurement bias. The frequency of symptoms was graded as follows: 1, less than once a month; 2 , once a month; 3 , once a week; 4 , several times a week; or 5 , daily. The severity was graded as follows: 1 , mild - can be ignored if I don't think about it; 2, moderate - cannot be ignored but does not affect my lifestyle; 3 , severe - affects my lifestyle; or 4 , very severe - noticeably affects my lifestyle.

The frequency and severity scores were added to compute combined scores for each symptom (ranges: heartburn score 0-9; acid regurgitation score $0-9$; and dysphagia score 0-9). Relevant current medication history (use of antacids, $\mathrm{H}_{2}$-receptor antagonists or proton pump inhibitors) was also obtained.

\section{ENDOSCOPY}

At endoscopy, macroscopic oesophagitis, if present, was noted and graded according to the Hetzel grading system ${ }^{23}$ as follows: grade 0 , normal appearing mucosa; grade 1 , mucosal oedema, hyperaemia, and/or friability of mucosa; grade 2, superficial erosions involving $<10 \%$ of mucosal surface of the distal 5 $\mathrm{cm}$ of oesophageal squamous mucosa; grade 3 , superficial erosions/ulcerations involving $10-50 \%$ of distal oesophagus; grade 4 , deep peptic ulceration anywhere in the oesophagus or confluent erosion of $>50 \%$ of the distal oesophageal squamous mucosa. The endoscopist was unaware of the symptom scores and histology results.

\section{HISTOLOGY}

In the absence of clinically apparent Barrett's oesophagus, two biopsy specimens of the gastro-oesophageal junction were taken in each patient. The gastro-oesophageal junction was identified by noting the change in colour between the squamous and columnar epithelium. The biopsy sample was carefully taken from a piece of the columnar epithelium immediately distal to the $z$-line. These samples were fixed with $10 \%$ buffered formalin and then embedded in paraffin wax. Serial sections were cut at three levels from each specimen. Sections were stained with haematoxylin and eosin (H\&E), alcian blue and Giemsa.

All sections were analysed independently for the presence of intestinal metaplasia, Helicobacter pylori and inflammation. The pathologists were unaware of the endoscopy and clinical data. On H\&E staining, intestinal metaplasia was considered to be present if goblet cells were identified based on their goblet cup like shape and characteristic staining (basal nucleus and clear spherical apical cytoplasm). ${ }^{13}$

Goblet cells contain acid mucin and stain intensely blue with alcian blue at $\mathrm{pH} 2 \cdot 5 .{ }^{24}{ }^{25}$ Columnar cells which stain less intensely with alcian blue are not diagnostic of Barrett's oesophagus as they can also be found in the mucus neck region of gastric glands. Positive identification of goblet cells with alcian blue in this study required the characteristic goblet shape and intense blue staining. ${ }^{4}$ Absence of either of the two characteristics negated the diagnosis of intestinal metaplasia in order to avoid overdiagnosis. A section of the small intestine was also stained simultaneously as a control.

$H$ pylori was identified by using the Giemsa stain using the criteria of its characteristic morphology (small curved basophilus bacillus), position and distribution (closely applied to epithelial cell surface, present within the pits and in overlying mucus). ${ }^{26}$

Inflammation at the gastro-oesophageal junction was diagnosed if increased numbers of lymphocytes and polymorphonuclear leucocytes were present in the lamina propria beneath the columnar epithelium. ${ }^{27}$ The Sydney System was used for the diagnosis of acute and chronic gastritis. ${ }^{28}$ Patients in whom both of the gastro-oesophageal junction biopsy specimens showed only stratified squamous epithelium but failed to include any columnar epithelium, were labelled as sampling error and were not included in the final analyses.

If endoscopically obvious Barrett's oesophagus was present (circumferential columnar lined oesophagus $>3 \mathrm{~cm}$ in length), patients did not undergo biopsy according to the protocol. Instead, biopsy specimens were taken as a part of a Barrett's oesophagus screening programme. These patients were not included in further analyses.

An additional biopsy specimen was also taken from the oesophagus, $2 \mathrm{~cm}$ above the gastro-oesophageal junction. This was processed in identical manner (see earlier), but stained with $\mathrm{H} \& \mathrm{E}$ only and graded independently. Oesophagitis was identified if there was (1) basal cell hyperplasia $>15 \%$ of the total epithelium, (2) increased papillary length $>66 \%$ of the squamous epithelium, and (3) infiltration by polymorphonuclear leucocytes or eosinophils, or both. ${ }^{29}$ At least two of the above findings had to be present for a positive diagnosis of microscopic oesophagitis. ${ }^{30} \mathrm{~A}$ separate analysis was carried out where all three criteria were required for diagnosis.

All biopsy specimens were scrutinised by two experienced pathologists. Any disagreement 
$(<5 \%)$ between the two investigators was resolved by consensus. Based on the presence or absence of intestinal metaplasia, patients were divided into those with and without short segment Barrett's oesophagus.

\section{PATIENT SELECTION}

From 1 April to 1 August 1995, 182 consecutive patients attending Nepean Hospital for upper endoscopy consented to enter the study. Only one patient declined for personal reasons. Of the 182 patients, four patients $(2 \cdot 2 \%)$ in whom the diagnosis of typical Barrett's oesophagus was made for the first time, during endoscopy, were excluded from

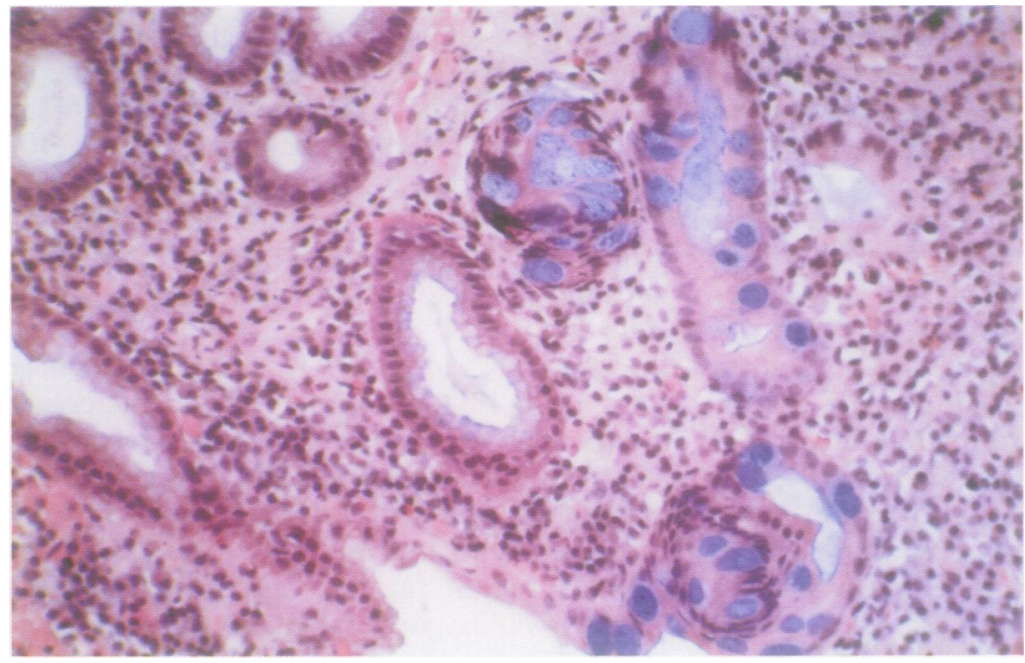

Figure 1: Biopsy sample from the gastro-oesophageal junction stained with alcian blue (pH 2.5) showing goblet cells with the characteristic features of intense blue staining and the typical spherical shape.

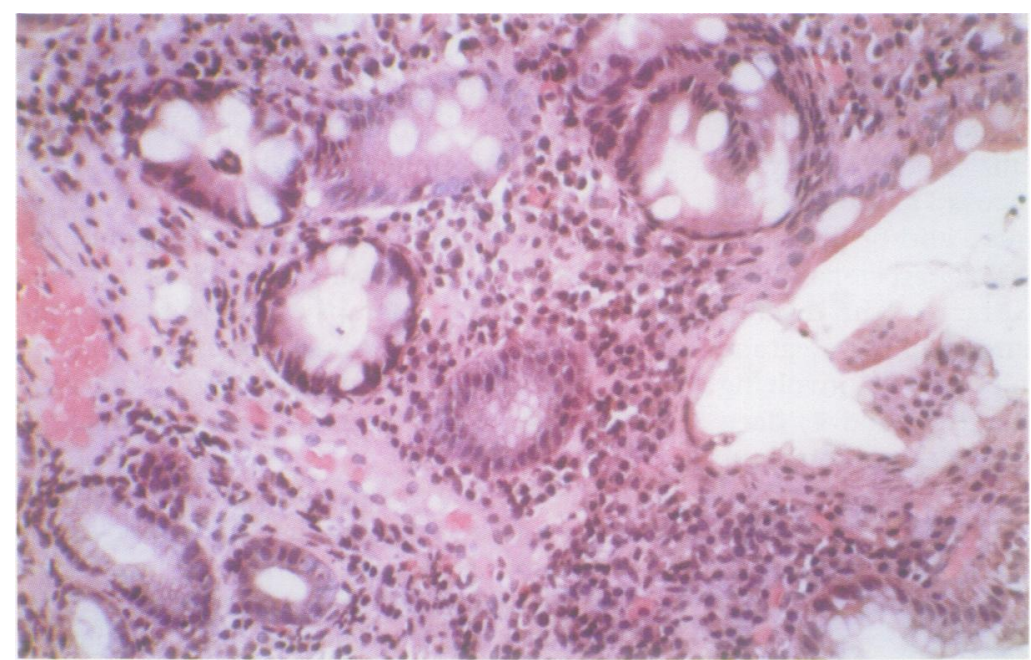

Figure 2: Biopsy sample from the gastro-oesophageal junction stained with haematoxylin and eosin showing goblet cells with the characteristic features of a basal nucleus and a clear spherical apical cytoplasm. further analysis. In a further 20 patients (11\%), the biopsy specimens contained only stratified squamous epithelium, indicating that the gastro-oesophageal junction was missed. Because of this sampling error, these specimens could not be evaluated for metaplasia and so the patients were excluded.

STATISTICAL ANALYSIS

Univariate and multiple logistic regression analyses were used to assess the relation between the prevalence of short segment Barrett's and age, sex, symptoms of gastrooesophageal reflux disease, medication, microscopic oesophagitis, inflammation of the gastro-oesophageal junction, and $H$ pylori status. Unadjusted and age adjusted odds ratios (OR) (with 95\% conficence intervals (CI)) are reported for each potential risk factor. Exact two-tailed p values, based on a Wald statistic, are reported which relate to the statistical Null hypothesis of a population odds ratio of unity. The independence of multiple risk factors was examined using forward stepwise selection of logistic regression models.

\section{Results}

PREVALENCE

In total, 158 patients were included in the final analysis (mean age 50.8 years; $66 \%$ women). Intestinal metaplasia was detected in 46 patients (prevalence rate $36 \%, 95 \%$ CI $28 \cdot 5-43 \cdot 5 \%$ ) by alcian blue staining. Metaplasia at the gastro-oesophageal junction was detected in both biopsy samples in $15(33 \%)$ patients and in one sample in $31(67 \%)$ patients.

COMPARISON OF H\&E AND ALCIAN BLUE STAINING

Figure 1 shows intestinal metaplasia as detected by staining with alcian blue. On H\&E staining alone (Fig 2), intestinal metaplasia was detected in only $23(15 \%)$ patients. There were no cases of intestinal metaplasia that were detected by $H \& E$ but missed by alcian blue staining. The prevalence of intestinal metaplasia detected by alcian blue and $H \& E$ staining is shown in Table I.

ASSOCIATIONS

Table II summarises the clinical features of the patients with and without short segment Barrett's oesophagus, and the univariate and age adjusted analyses. The patients with intestinal metaplasia as a group were older than those without $(p=0 \cdot 009)$. However, there was no difference in the sex ratios between the two groups.

Symptom scores constructed from the reflux questionnaire did not differ between the two groups. Erosive oesophagitis (Hetzel grade $>1$ ) was more prevalent in the group with intestinal metaplasia $(24 \%$ v $14 \%)$. However, adjusting for age, this difference did not reach statistical
TABLE I Comparison of alcian blue and haematoxylin and

\begin{tabular}{lll}
\hline & \multicolumn{2}{l}{ Haematoxylin and eosin } \\
\cline { 2 - 3 } & Positive $(n)$ & Negative $(n)$ \\
\hline Alcian blue: & 23 & 23 \\
Positive & 0 & 112 \\
Negative & 0 &
\end{tabular}


TABLE II Characteristics of patients $(n=158)$ with and without short segment Barrett's oesophagus

\begin{tabular}{|c|c|c|c|c|}
\hline & \multicolumn{2}{|c|}{$\begin{array}{l}\text { Short segment Barrett's } \\
\text { oesophagus }\end{array}$} & \multicolumn{2}{|l|}{ p Value } \\
\hline & $\begin{array}{l}\text { Positive } \\
(n=46)\end{array}$ & $\begin{array}{l}\text { Negative } \\
(n=112)\end{array}$ & Univariate & $\begin{array}{l}\text { Adjusted } \\
\text { for age* }\end{array}$ \\
\hline Mean age (years) & $55 \cdot 7$ & $47 \cdot 9$ & 0.009 & 0.009 \\
\hline Women $(\%)$ & $65 \cdot 2$ & $68 \cdot 3$ & 0.92 & 0.89 \\
\hline Mean heartburn score (range: $0-9$ ) & 7 & $6 \cdot 8$ & 0.69 & 0.84 \\
\hline $\begin{array}{l}\text { Mean acid regurgitation score } \\
\text { (range: } 0-9 \text { ) }\end{array}$ & $5 \cdot 2$ & $5 \cdot 7$ & 0.46 & 0.55 \\
\hline Mean dysphagia score (range: $0-9$ ) & $5 \cdot 1$ & $4 \cdot 8$ & $0 \cdot 89$ & $0 \cdot 88$ \\
\hline \multicolumn{5}{|l|}{ Treatment $(\%)$ : } \\
\hline No treatment & $40 \cdot 2$ & 37 & 0.71 & 0.87 \\
\hline $\mathrm{H}_{2}$-receptor antagonists $\left(\mathrm{H}_{2} \mathrm{RA}\right)$ & $45 \cdot 5$ & 50 & 0.61 & 0.49 \\
\hline Proton pump inhibitors (PPI) & 8.9 & $8 \cdot 7$ & 0.96 & 0.86 \\
\hline $\mathrm{H}_{2}$ RA and PPI & $5 \cdot 4$ & $4 \cdot 3$ & 0.79 & 0.54 \\
\hline Macroscopic oesophagitis (\%) & - & - & 0.07 & $0 \cdot 13$ \\
\hline No oesophagitis & $60 \cdot 9$ & $69 \cdot 6$ & - & - \\
\hline \multicolumn{5}{|l|}{ Oesophagitis: } \\
\hline Grade 1 & $15 \cdot 2$ & $16 \cdot 1$ & - & - \\
\hline Grade 2 & $8 \cdot 7$ & 8.9 & - & - \\
\hline Grade 3 & 10.9 & $3 \cdot 6$ & - & - \\
\hline Grade 4 & $4 \cdot 3$ & $1 \cdot 8$ & - & - \\
\hline Basal cell hyperplasia (\%) & 54 & 21 & $<0.001$ & $<0.001$ \\
\hline Increased papillary length (\%) & 41 & 20 & 0.008 & 0.004 \\
\hline $\begin{array}{l}\text { Infiltration with neutrophils/ } \\
\text { eosinophils }(\%)\end{array}$ & 32 & 14 & 0.01 & 0.006 \\
\hline $\begin{array}{l}\text { Microscopic oesophagitis (\%) } \\
\text { ( } \geq 2 \text { criteria present) }\end{array}$ & 43 & 19 & 0.001 & 0.001 \\
\hline $\begin{array}{l}\text { Microscopic oesophagitis (\%) } \\
\text { (all } 3 \text { criteria present) }\end{array}$ & 28 & 13 & 0.02 & 0.01 \\
\hline $\begin{array}{l}\text { Gastro-oesophageal junction: } \\
\text { inflammation }(\%)\end{array}$ & 87 & 50 & $<0.001$ & $<0.001$ \\
\hline $\begin{array}{l}\text { Gastro-oesophageal junction: } \\
\text { H pylori (\%) }\end{array}$ & 13 & 17 & 0.54 & 0.56 \\
\hline
\end{tabular}

${ }^{\star} \mathrm{p}$ Values were obtained from a logistic regression analysis adjusted for age.

significance (OR $1 \cdot 4,95 \%$ CI $0.9-2 \cdot 3$, $\mathrm{p}=0 \cdot 13)$. Histological oesophagitis was associated with short segment Barrett's oesophagus (OR 3.9, 95\% CI 1.8-8.7, p=0.001). When data were re-analysed using the presence of all three criteria for the diagnosis of histological oesophagitis, the association was strengthened when adjusted for age (OR 3.25, 95\% CI 1.3-7.9, p=0.01). Short segment Barrett's oesophagus was also strongly associated with inflammation at the gastro-oesophageal junction when adjusted for age (OR 6.7, 95\% CI $2 \cdot 6-17 \cdot 3, p<0 \cdot 001)$. Short segment Barrett's oesophagus was not associated with medication use or the presence of $H$ pylori at the gastro-oesophageal junction.

Logistic regression analysis confirmed that age (OR per decade $1 \cdot 03,95 \%$ CI $1 \cdot 01-1 \cdot 06$, $\mathrm{p}=0.005$ ), histological oesophagitis (OR 3.2, $95 \%$ CI $1 \cdot 4-7 \cdot 2, p=0 \cdot 006$ ), and inflammation at the gastro-oesophageal junction (OR 5.9, $95 \%$ CI $2 \cdot 2-15 \cdot 6, \mathrm{p}<0 \cdot 001)$ were independent risk factors for short segment Barrett's oesophagus.

\section{Discussion}

Intestinal metaplasia characterised by the presence of goblet cells is the sine qua non for the diagnosis of short segment Barrett's oesophagus. Other types of epithelium that are found in standard Barrett's oesophagus such as junctional or fundic mucosa are per se not diagnostic of Barrett's oesophagus as they can occur in the distal oesophagus of people without the condition. ${ }^{3}$ In our study, we found that one in three patients presenting for endoscopy had intestinal metaplasia. This prevalence is higher than that published in the
USA, ${ }^{13}{ }^{14}$ in which $H \& E$ was the sole staining method used to detect intestinal metaplasia. This discrepancy is explained by our use of alcian blue which seemed to be superior to staining with $H \& E$. In our study, the prevalence of intestinal metaplasia using $\mathrm{H} \& \mathrm{E}$ alone was $15 \%$, which is comparable with the prevalence described by Spechler et al. ${ }^{13} \mathrm{We}$ found no cases of intestinal metaplasia that were detected by $H \& E$ but missed by alcian blue. We do not believe that the additional cases detected by alcian blue were likely to be false positives because we adhered to strict criteria for diagnosis.

Our results are consistent with the application of alcian blue staining in other settings. Cooper et al obtained biopsy samples from 11 children (mean age 5.9 years) with standard Barrett's oesophagus. ${ }^{31}$ They identified five additional cases of specialised intestinal epithelium on staining with alcian blue that were missed with $\mathrm{H} \& \mathrm{E}$ staining. Gottfried et al, too, found alcian blue to be more sensitive than $\mathrm{H} \& \mathrm{E}$ in the diagnosis of intestinal metaplasia. ${ }^{4}$ When strict criteria were used (that is, rejection of patients showing only diffuse acid mucin in the columnar cells with alcian blue), they concluded that goblet cell metaplasia detected by alcian blue is highly specific for the histological diagnosis of columnar lined (Barrett's) oesophagus. Because we used strict criteria in our study for the positive identification of goblet cells, we may have actually underestimated the prevalence of short segment Barrett's oesophagus, but we believe that any such error would be small. We recommend that alcian blue be used as a routine stain in the diagnosis of short segment Barrett's oesophagus.

We found that the prevalence of short segment Barrett's oesophagus was higher in older subjects. Epidemiological studies by Cameron $e^{2} \mathrm{al}^{32}$ and GOSPE ${ }^{33}$ have shown that standard Barrett's oesophagus is also age dependent. This supports the view that both these conditions are acquired. We adjusted for age in our analyses as this may have otherwise confounded our results.

A causal relation between gastro-oesophageal reflux disease and standard Barrett's oesophagus is believed to exist in humans, ${ }^{16-18}$ and refluxate has been used to induce Barrett's mucosa in experimental models. ${ }^{19-22}$ Nakano et al subjected Wistar rats to gastrectomy and an end to side anastomosis between the oesophagus and jejunum, resulting in free jejuno-oesophageal reflux. ${ }^{22}$ They showed the appearance of columnar epithelium in the oesophagus replete with absorptive and goblet cells. These goblet cells were positively identified on staining with high iron diamine/alcian blue and concanavalin A type III. Martin et al performed gastroenterostomy and cardioplasty in dogs to promote free pancreaticoduodenal reflux into the oesophagus. ${ }^{21}$ Gastric acid secretion was inhibited with an oral proton pump inhibitor (omeprazole $\sim 40 \mu \mathrm{mol} / \mathrm{kg} / \mathrm{day})$. The oesophageal mucosa was resected and allowed to heal in this modified environment. They noted healing 
with squamous epithelium at the proximal border whereas distal healing occurred with a columnar epithelium (with goblet cells). Barrett's epithelium has also been reported as a consequence of acid reflux after oesophageal myotomy in patients with achalasia. ${ }^{34}$

It has been hypothesised that destruction of the stratified squamous epithelium and the subsequent repair process leads to the development of islands of intestinal metaplasia in the oesophagus. We identified a trend $(24 \% v$ $14 \%$ ) for erosive oesophagitis to be associated with short segment Barrett's oesophagus. The lack of statistical significance may reflect a type II error; we calculate, based on our results, that a population of 390 patients would be needed to detect a difference of $20 \%$ with a power of $80 \%$. Histological changes in the oesophagus such as basal cell hyperplasia, increased papillary length and infiltration by neutrophils or eosinophils, or both, have been reported to be useful predictors of pathological acid reflux, although this is controversial. ${ }^{35}$ In a study by Ismail-Beigi et al these changes were present in $85 \%$ of patients with symptomatic reflux, based on history and a short $\mathrm{pH}$ study, and in $10 \%$ of normal controls. ${ }^{30}$ In our study, histological oesophagitis was a more sensitive marker of reflux disease than macroscopic changes. We believe that these histological changes suggest that gastro-oesophageal reflux disease is linked to short segment Barrett's oesophagus, but further studies are needed using 24 hour oesophageal $\mathrm{pH}$ monitoring. We found, however, that the symptoms of gastrooesophageal reflux disease were not associated with the presence of short segment Barrett's oesophagus, consistent with an earlier study. ${ }^{13}$ This may reflect the lack of sensitivity of symptoms in general in identifying the presence of Barrett's oesophagus. ${ }^{33}$

We found that inflammation in the columnar epithelium at the gastro-oesophageal junction had the strongest association with intestinal metaplasia. An increased prevalence of inflammation at the gastro-oesophageal junction in patients with short segment Barrett's oesophagus was also noted by Clark et al. ${ }^{14}$ In their preliminary study, ambulatory 24 hour $\mathrm{pH}$ testing showed increased exposure to oesophageal acid in a cohort of patients with short segment Barrett's oesophagus. In contrast to the present study, when inflammation at the gastro-oesophageal junction and histological oesophagitis were analysed together, only inflammation at the gastro-oesophageal junction remained statistically significant. We hypothesise that inflammation at the gastrooesophageal junction acts as a nidus for metaplastic change. The exact cell of origin of Barrett's oesophagus is unknown but undifferentiated pluripotent stem cells, basal cells of squamous epithelium and epithelial cells, and congenital gastric rests are all candidates. Epidermal growth factor receptor (EGFr) is concentrated in the basal and prickle cell layers of oesophageal epithelium as well as in Barrett's mucosa. ${ }^{36} 37$ Acid stimulates EGFr which in turn seems to be involved in cellular proliferation and maturation, stimulating wound healing and maintaining tissue integrity. ${ }^{36}{ }^{37}$ Hence, it can be postulated that inflammation at the gastro-oesophageal junction secondary to reflux of acid and possibly duodenal juice may activate EGFr (and possibly other cytokines) which in turn induces cellular dedifferentiation leading to intestinal metaplasia.

We did not find any difference in the prevalence of $H$ pylori at the gastro-oesophageal junction in the patients with and without short segment Barrett's oesophagus. We had postulated that a higher local prevalence of $H$ pylori in patients with short segment Barrett's may account for increased inflammatory changes at the gastro-oesophageal junction. As the antrum and the corpus were not sampled, it is likely that we have underestimated the prevalence of $H$ pylori distally. However, increased detection of $H$ pylori from the antrum would not necessarily negate reflux as a causal possibility as $H$ pylori can coexist in patients with gastro-oesophageal reflux disease without being linked causally to the latter. We suspect that gastro-oesophageal reflux disease rather than $H$ pylori is the underlying pathophysiological mechanism causing inflammation at the gastro-oesophageal junction in patients with intestinal metaplasia.

Although there was an age related increase in prevalence in standard Barrett's oesophagus in one large study, no significant increase in length was noticed. ${ }^{32}$ This report suggested that standard Barrett's oesophagus develops to its full length all at once, usually many years before it is diagnosed, with no significant further increment in its length with time. Whether short segment Barrett's oesophagus is a completely separate entity or a precursor lesion for typical Barrett's oesophagus is unknown, but the former seems more likely based on the data available.

A significant increase in the incidence of oesophageal adenocarcinoma has been noted in the past few decades, ${ }^{38}{ }^{39}$ and these tumours are almost always associated with underlying specialised intestinal type epithelium rather than junctional or fundic type. ${ }^{10}{ }^{11}$ Anecdotal evidence based on case reports supports the view that adenocarcinoma is associated with short segment Barrett's oesophagus. ${ }^{6}{ }^{12}$ The very high prevalence of short segment Barrett's oesophagus may therefore be of clinical importance. There are no studies which have determined the cumulative risk of development of adenocarcinoma in patients with short segment Barrett's oesophagus. Moreover, the natural history of short segment Barrett's oesophagus has not been characterised carefully. Further studies are required before it will be known whether guidelines for surveillance in patients with short segment Barrett's oesophagus will need to be developed.

We thank Dr M Jones PhD and Dr J Bai MPH for their assistance with the statistical analyses. We also thank Drs L Brooks, A Keegan and M Cox for their help in providing us $\mathrm{L}$ Brooks, A Keegan and $M$
with patients for the study.

1 Stein HJ, Siewart JR. Barrett's esophagus: pathogenesis, epidemiology, functional abnormalities, malignan degeneration, and surgical management. Dysphagia 1993; 8: $276-88$. 
2 Spechler SJ, Goyal RK. Barrett's esophagus. N Engl $\mathcal{F}$ Med 1986; 315: 362-71.

3 Haggitt RC. Barrett's esophagus, dysplasia, and adenocarcinoma. Hum Pathol 1994; 25: 982-93.

4 Gottfried MR, McClave SA, Boyce HW. Incomplete intestinal metaplasia in the diagnosis of columnar lined esophagus (Barrett's esophagus). Am F Clin Pathol 1989, 92: 741-6.

5 Pera M, Cameron AJ, Trastek VF, Carpenter HA Zinsmeister AR. Increasing incidence of adenocarcinoma of the esophagus and esophagogastric junction. Gastroenterology 1993; 104: 510-3.

6 Schnell TG, Sontag SJ, Chejfec G. Adenocarcinomas arising in tongues of short segments of Barrett's esophagus. Dig Dis Sci 1992; 37: 137-43.

7 Hamilton SR, Smith RR, Cameron JL. Prevalence and characteristics of Barrett's esophagus in patients with characteristics of Barrett's esophagus in patients with
adenocarcinoma of the esophagus or esophagogastric adenocarcinoma of the esophagus

8 Clark GWB, Smyrk TC, Burdiles P, Hoeft SF, Peters JH, Kiyabu M, et al. Is Barrett's metaplasia the source of adenocarcinomas of the cardia? Arch Surg 1994; 129 609-14.

9 Thompson JJ, Zinsser KR, Enterline HT. Barrett's metaplasia and adenocarcinoma of the esophagus and gastroesophageal junction. Hum Pathol 1983; 14: 42-61.

10 Skinner DB, Walther BC, Riddell RH, Schmidt $H$, Lascone C, DeMeester TR. Barrett's esophagus: comparison of benign and malignant cases. Ann Surg 1983; 198: 554-66.

11 Hamilton ST, Smith RR. The relationship between columnar epithelial dysplasia and invasive adenocarcinoma arising in Barrett's esophagus. Am $\mathcal{f}$ Clin Patho 1987; 87: 301-12.

12 Cameron AJ, Lomboy CT, Pera M, Carpenter HA Adenocarcinoma of the esophagogastric junction and Barrett's esophagus. Gastroenterology 1995; 109: 1541-6.

13 Spechler SJ, Zeroogian JM, Antonioli DA, Wang $\mathrm{HH}$ Goyal RK. Prevalence of metaplasia at the gastrooesophageal junction. Lancet 1994; 344: 1533-6.

14 Clark GWB, Ireland AP, Chandrasoma P, DeMeester TR, Peters JH, Bremner CG. Inflammation and metaplasia in the transitional epithelium of the gastroesophageal the transitional epithelium of the gastroesophageal junction: a new marker for gastroesophageal

15 Cooper JE, Spitz L, Wilkins BM. Barrett's oesophagus in children. A histologic and histochemical study of 11 cases. $\Im$ Pediatr Surg 1987; 3: 191-6.

16 DeMeester TR, Attwood SEA, Smyrk RC, Therkildsen DH, Hinder RA. Surgical therapy in Barrett's esophagus. Ann Surg 1990; 212: 528-40.

17 Bozymski EM, Herlihy KJ, Orlando RC. Barrett's esophagus. Ann Intern Med 1982; 97: 103-7.

18 Winters C, Spurling TJ, Chobanian S, Curtis DJ, Esposito RL, Hacker JF, et al. Barrett's esophagus: a prevalent, occult complication of gastroesophageal reflux disease. Gastroenterology 1987; 92:118-24.

19 Fink MA, Martin CJ, Ewing HP, Machet D, Rode J. A longitudinal study of the development of experimental Barrett's oesophagus in

20 Poliness CM, Martin CJ, Ewing HP, Thompson ME, Machet D, Rode J. Bile affects the pattern of metaplasia in experimental columnar lined oesophagus [abstract] Gastroenterology 1993; 104: A173.
21 Martin CJ, Shaw ME, Ewing HP, Machet D. Pancreatic reflux produces intestinal metaplasia in experimental reflux produces intestinal metaplasia in experimental 1995; 65: A422.

22 Nakano $K$, Sato $H$, Kimura $T$, Noda $M$, Kodama $T$, Kashima $\mathrm{K}$, et al. An experimental model of Barrett's esophagus by jejunoesophageal reflux [abstract]. Gastroenterology 1996; 110: A206.

23 Hetzel DJ, Dent J, Reed WD, Narielwala FM Mackinnon M, McCarthy JH, et al. Healing and relapse of severe peptic esophagitis after treatment with omeprazole. Gastroenterology 1988; 95: 903-12.

24 Rothery GA, Patterson JE, Stoddard CJ, Day DW. Histological and histochemical changes in the columnar lined (Barrett's) oesophagus. Gut 1986; 27: 1062-8.

25 Peuchmaur M, Potet F, Goldfain D. Mucin histochemistry of the columnar epithelium of the esophagus (Barrett's osophagus): a prospective biopsy study. $\mathcal{f}$ Clin Pathol 1984; 37: 607-10.

26 Wyatt JI, Gray SF. Detection of Helicobacter pylori by histology. In: Rathbone BJ, Heatley RV, eds. Helicobacte pylori and gastroduodenal disease. Oxford: Blaxwell Scientific Publications, 1992: 51-7.

27 Robert ME, Weinstein WM. Helicobacter pylori associated gastric pathology. Gastroenterol Clin North Am 1993; 22 59-72.

28 Misiewicz J, Tytgat GNJ, Price AB, Goodwin CS, Strickland RG, Sipponen P. The Sydney System: A new classification of gastritis. $\mathcal{F}$ Gastroenterol Hepatol 1991; 6: 207-8.

29 Frierson HF. Histology in the diagnosis of reflux esophagitis. Gastroenterol Clin North Am 1990; 19: 631-44.

30 Ismail-Beigi F, Horton PF, Pope CE. Histological consequences of gastro-esophageal reflux in man. Gastroenterology 1970; 58: 163-74.

31 Cooper JE, Spitz L, Wilkins BM. Barrett's oesophagus in children. A histologic and histochemical study of 11 cases. f Pediatr Surg 1987; 3: 191-6.

32 Cameron AJ, Lomboy CT. Barrett's esophagus: Age, prevalence and extent of columnar epithelium. Gastroenterology 1992; 103: 1241-5.

33 Gruppo Operativo Per Lo Studio Della Precancerosi Dell 'Esofago (GOSPE). Barrett's esophagus: Epidemiological and clinical results of a multicentric survey. Int $₹$ Cancer and clinical results

34 Agha FP. Barrett's esophagus complicating achalasia after esophagomyotomy. A clinical, radiologic and pathologic study of 70 patients with achalasia and related moto disorders. F Clin Gastroenterol 1987; 9: 232-7.

35 Schindlbeck NE, Wiebecke B, Klauser AG, Voderholzer WA Muller-Lissner SA. Diagnostic value of histology in nonerosive gastro-oesophageal reflux disease. Gut 1996; 39: $151-4$.

36 Jankowski J, Murphy S, Coghill G, Grant A, Wormsley KG, Sanders DSA, et al. Epidermal growth factor receptors in the oesophagus. Gut 1992; 33: 439-43.

37 Jankowski J, Coghill G, Tregakis B, Hopewood D, Wormsley KG. Epidermal growth factor in the oesophagus. Gut 1992; 33: 1448-53.

38 Hansson L-E, Sparén P, Nyrén O. Increasing incidence of carcinoma of the gastric cardia in Sweden from 1970 to 1985. Br ₹ Surg 1993; 80: 374-7.

39 Blot WJ, Devesa SS, Kneller RW, Fraumeni JF. Rising incidence of adenocarcinoma of the esophagus and gastric cardia. FAMA 1991; 265: 1287-9. 